\title{
Managing severe pain and abuse potential: the potential impact of a new abuse- deterrent formulation oxycodone/naltrexone extended-release product
}

This article was published in the following Dove Press journal:

Journal of Pain Research

\author{
Joseph V Pergolizzi, Jr' \\ Robert Taylor Jr' \\ Jo Ann LeQuang' \\ Robert B Raffa ${ }^{2,3}$ \\ On behalf of the NEMA \\ Research Group \\ 'NEMA Research Inc., Naples, FL, \\ USA; ${ }^{2}$ University of Arizona College \\ of Pharmacy, Tucson, AZ, USA; ${ }^{3}$ Temple \\ University School of Pharmacy, \\ Philadelphia, PA, USA
}

Correspondence: Robert B Raffa 3825 E Diablo Canyon Place, Tucson, AZ 85718, USA

Email robert.raffa@temple.edu

\begin{abstract}
Proper management of severe pain represents one of the most challenging clinical dilemmas. Two equally important goals must be attained: the humanitarian/medical goal to relieve suffering and the societal/legal goal to not contribute to the drug abuse problem. This is an age-old problem, and the prevailing emphasis placed on one or the other goal has resulted in pendulum swings that have resulted in either undertreatment of pain or the current epidemic of misuse and abuse. In an effort to provide efficacious strong pain relievers (opioids) that are more difficult to abuse by the most dangerous routes of administration, pharmaceutical companies are developing products in which the opioid is manufactured in a formulation that is designed to be tamper resistant. Such a product is known as an abuse-deterrent formulation (ADF). ADF opioid products are designed to deter or resist abuse by making it difficult to tamper with the product and extracting the opioid for inhalation or injection. To date, less than a dozen opioid formulations have been approved by the US Food and Drug Administration to carry specific ADF labeling, but this number will likely increase in the coming years. Most of these products are extended-release formulations.
\end{abstract}

Keywords: oxycodone/naltrexone, abuse-deterrent formulation, abuse-deterrent opioid, oxycodone, abuse liability

\section{Introduction}

Opioids are indicated for the treatment of many forms of acute and chronic severe pain, but the abuse potential of opioids can make it challenging to offer them to patients at elevated risk for opioid misuse and abuse. Increasingly, clinicians face having to treat severe pain in patients at risk for opioid abuse or even with active substance abuse disorders. The emerging new category of abuse-deterrent formulations (ADFs) of opioid analgesics plays a major role in intending to provide analgesic benefit to patients, while deterring the potential that the oral analgesics can be crushed or dissolved (and thus cannot be smoked, inhaled, or drawn up into a syringe). The US Food and Drug Administration (FDA) has endorsed the development of ADF opioids. ${ }^{1}$

ALO-02 (Troxyca ${ }^{\circledR}$ ER; Pfizer, New York, NY, USA) is a novel ADF analgesic product that combines a fixed dose of extended-release (ER) oxycodone (60 or 80 $\mathrm{mg}$ ) plus the opioid antagonist naltrexone (7.2 or $9.6 \mathrm{mg}$, respectively) in a single oral pill designed to resist tampering efforts. It relies on similar technology used in another commercial product with ER morphine. ALO-02 contains tiny pellets of ER oxycodone surrounding a core of sequestered naltrexone $12 \%$ (Figure 1 ). If the product 


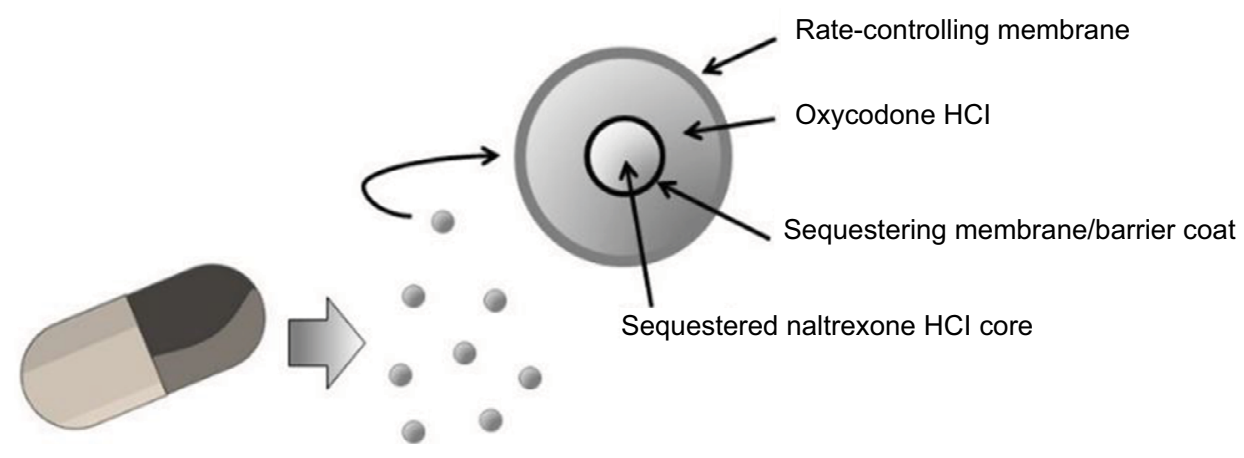

Figure I ALO-02 is an oxycodone analgesic product with a sequestered opioid antagonist (naltrexone).

is tampered with in an effort to obtain oxycodone, naltrexone may be released, which will block the opioid receptors (through which oxycodone produces its effects) and dampen the potential psychoactive effects of oxycodone. ALO-02 is intended for administration twice daily (every 12 hours) as an oral agent. It joins nearly a dozen other ADF products in the analgesic armamentarium. As opioids increasingly come under scrutiny for their abuse potential, it is of concern as to whether this new product adds versatility to clinical management of severe pain or it is joining an already overcrowded field. It is our aim in this narrative review to consider the evidence for and against this product and its potential role in the treatment of severe pain.

\section{Materials and methods}

On May 29, 2017, the PubMed, Embase, and Cochrane databases were searched using the term "oxycodone + naltrexone + pain" anywhere in the article and 35 results (PubMed), 0 (Embase), and 22 results (Cochrane Library) were obtained. No delimiters were used in the search which included all types of papers without restriction to publication date. In some instances, the bibliographies of these papers were also searched. Our goal was to create a narrative rather than a systematic review.

\section{Abuse-deterrent products}

ADFs of opioids are defined by the FDA as products which meet specific criteria aimed at resisting or deterring abuse. Four categories have been defined by the FDA based on the source of the evidence for abuse deterrence: drug formulations that resist in vitro manipulation and extraction; pharmacokinetic studies and in vivo properties of tampered dosages versus the intact product and a comparator; clinical abuse trials among recreational drug users; and postmarketing studies aimed at ascertaining the impact of an ADF product on abuse, misuse, and adverse outcomes. ADF labeling approved by the FDA is based on the information supplied by the sponsor regarding ADF tests that a particular product is able to pass. A variety of ADF technologies have come to market in the past decades, including those that make use of a physical barrier (making the product crush resistant or incapable of being dissolved), a chemical barrier, an aversive agent (such as capsaicin or niacin), and an opioid antagonist. ALO-02 relies on the strategy of combining an opioid agonist with an antagonist. Other ADF products using the opioid agonist/antagonist design are listed in Table 1.

The design of the agonist/antagonist combination may be accomplished in one of two ways: the antagonist may be released ("available"), but does not affect the agonist when the drug is taken properly, or the antagonist may be sequestered. "Available" antagonists are absorbed by the body when the drug is taken as prescribed. For example, a small amount of naloxone would be metabolized extensively in the first pass when the drug is taken orally with bioavailability of $<2 \%$; it would have virtually no effect on the agonist. ${ }^{2}$ On the other hand, a "sequestered" antagonist is not intended to be metabolized during appropriate oral ingestion, but would pass through the body. If the drug is manipulated, the sequestered antagonist would be released. The bioavailability of naltrexone is much greater than that of naloxone and, as a result, agonist/antagonist combination products using naltrexone must rely on sequestration. ${ }^{2}$

\section{A short history of agonist/antagonist ADF opioid analgesics}

In 1969, Talwin ${ }^{\circledR} 50$, a conventional oral formulation of 50 mg pentazocine hydrochloride, was approved in the USA for pain control. The drug became a target for abusers who found they could crush the pills easily (for inhalation) or dissolve them (for injection). This led to an abuse craze known as T's \& B's (also Tops \& Bottoms, T-shirts and Blue Jeans, and other slang terms) in which pentazocine (the $\mathrm{T}$ is taken from Talwin, the brand name) was combined with the first-generation antihistamine tripelennamine (trade name Pyribenzamine ${ }^{\circledR}$ ), a blue tablet. Although T's \& B's could be taken orally, the preferred route of administration 
Table I ADF and related products in which an opioid agonist and an antagonist are combined

\begin{tabular}{|c|c|c|c|c|}
\hline Agonist & Antagonist & Technology & Brand name, manufacturer & Comment \\
\hline Buprenorphine & Naloxone & $\begin{array}{l}\text { IR tablet and film with } \\
\text { sequestered antagonist (film uses } \\
\text { casing) }\end{array}$ & $\begin{array}{l}\text { Suboxone }{ }^{\circledR} \text {, Reckitt Banckiser } \\
\text { Pharmaceuticals, Inc. }\end{array}$ & $\begin{array}{l}\text { Not approved for use in pain } \\
\text { syndromes }\end{array}$ \\
\hline Buprenorphine & Naloxone & IR film with BEMA technology & $\begin{array}{l}\text { Bunavai }{ }^{\circledR} \text { buccal film, } \\
\text { BioDelivery Sciences } \\
\text { International, Inc. }\end{array}$ & Approved in 2014 \\
\hline Buprenorphine & Naloxone & $\begin{array}{l}\text { IR tablet with lower dose than } \\
\text { Suboxone }\end{array}$ & Zubsolve $^{\circledR}$, Orexo AB & Approved in 2013 \\
\hline Morphine sulfate & Naltrexone & $\begin{array}{l}\text { Coated ER beads of morphine } \\
\text { layered onto a sequestered core } \\
\text { of antagonist }\end{array}$ & $\begin{array}{l}\text { Embeda }^{\circledR} \text { ER capsule, King } \\
\text { Pharmaceuticals since acquired } \\
\text { by Pfizer, Inc. }\end{array}$ & Approved in 2009 \\
\hline Oxycodone & Naloxone & Crush-resistant technology & $\begin{array}{l}\text { Targiniq }{ }^{\circledR} \text { ER tablet, Purdue } \\
\text { Pharma }\end{array}$ & Approved in 2014 \\
\hline Oxycodone & Naltrexone & $\begin{array}{l}\text { ER oral capsules with film-coated } \\
\text { beads, each of which has a core of } \\
\text { sequestered naltrexone }\end{array}$ & $\begin{array}{l}\text { Troxyca }{ }^{\circledR} \text { ER (ALO-02), Pfizer, } \\
\text { Inc. }\end{array}$ & $\begin{array}{l}\text { Approved in 20I6; uses same ADF } \\
\text { technology as Embeda ER }\end{array}$ \\
\hline Oxycodone & Naltrexone & $\begin{array}{l}\text { Ultra-low dose of naltrexone } \\
(0.0001 \text { or } 0.001 \mathrm{mg})\end{array}$ & Oxytrex, Pain Therapeutics, Inc. & $\begin{array}{l}\text { This is not an ADF product; the } \\
\text { addition of naltrexone is intended to } \\
\text { enhance analgesic effect; investigational } \\
\text { drug }\end{array}$ \\
\hline $\begin{array}{l}\text { Pentazocine } \\
\text { hydrochloride }\end{array}$ & Naloxone & IR tablet with naloxone & Talwin ${ }^{\circledast}$, Sanofi Aventis & $\begin{array}{l}\text { Approved in } 1982 \text {, not technically an } \\
\text { ADF product, but the manufacturer } \\
\text { used a reformulation to make it more } \\
\text { difficult to abuse drug }\end{array}$ \\
\hline
\end{tabular}

Note: Data from Maincent and Zhang. ${ }^{2}$

Abbreviations: ADF, abuse-deterrent formulation; BEMA, BioErodible MucoAdhesive; ER, extended release; IR, immediate release.

among the most ardent abusers was intravenous (IV) injection. ${ }^{3}$ T's \& B's were easy to abuse by injection in that no heating of the formulation was required. The formulation could be crushed, mixed with tap water, and then shaken before being drawn through cotton into a syringe in a process nicknamed a "cold shake". ${ }^{3}$ So popular were T's \& B's that one hard-hit Chicago rehabilitation clinic reported that around 1979, about $10 \%$ of its treatment clinic work was devoted to the abuse of this particular drug combination. ${ }^{3}$ To help deter abuse, Talwin's manufacturer, Winthrop Laboratories, worked with the FDA and introduced a nextgeneration version of the product marketed as Talwin $\mathrm{Nx}$, an oral fixed-dose combination product of $50 \mathrm{mg}$ pentazocine plus $0.5 \mathrm{mg}$ naloxone. ${ }^{4}$ When taken orally, the small amount of naloxone produced virtually no effect owing to its low bioavailability, but when the drug was dissolved and injected IV or intramuscularly, naloxone was released in sufficient amounts to counter the psychoactive effects of opioids. When Talwin Nx was introduced to market, the previousgeneration Talwin 50 product was discontinued. In the 2 years following the introduction of Talwin Nx to market, emergency room mentions and medical examiner mentions for Talwin decreased by $70 \%$ and $71 \%$, respectively, although the prescription rates for Talwin Nx increased slightly versus Talwin 50 in that same time frame. ${ }^{5}$
At the time Talwin Nx was approved in 1982, the concept of ADF as a product category was unknown and the product carried no special ADF labeling. Talwin Nx was the manufacturer's response to a public health problem. Unfortunately, it was still possible to abuse Talwin Nx by taking it orally. ${ }^{4,6}$

Suboxone ${ }^{\circledR}$ (Reckitt Benckiser, Slough, Berkshire, UK) came to market in 2002 as a sublingual tablet of immediaterelease (IR) buprenorphine combined with naloxone and indicated for the treatment of opioid dependence. In 2010, Suboxone sublingual film was introduced to make dosing easier and more convenient. This was an important agonist/ antagonist combination product, but it had no labeled indication for pain treatment.

In 2010, King Pharmaceuticals developed Embeda ${ }^{\circledR}$, a morphine ER capsule with sequestered naltrexone based on a proprietary coating technology. The use of naltrexone required that the antagonist be sequestered. When taken intact as an oral pill, the naltrexone passes through the body without effect; when the drug is manipulated, the naltrexone is released.

OxyContin $^{\circledR}$, a proprietary ER formulation of oxycodone, was cleared for market release in the USA in 1995. It became a frequently abused drug and was reformulated in 2010 in a crush-resistant ADF formulation as OxyContin 
OP (sometimes called the "new oxy"). The abuse-deterrent version of OxyContin could still be abused by taking it intact orally, but oxycodone was frequently and by some abusers preferentially abused via non-oral routes. In a study of opioid rehabilitation patients who abused oxycodone, $88 \%$ said they primarily abused oxycodone by non-oral routes of administration, such as inhalation (snorting) or injection. ${ }^{7}$ The introduction of OxyContin OP disrupted these abuse patterns. First, ADF oxycodone decreased overall abuse for oxycodone as evaluated in abuse statistics from the past 30 days at rehabilitation treatment centers. ${ }^{8}$ Second, it shifted abuse of oxycodone to oral ingestion (76.1\%) compared to snorting $(25.4 \%)$ or injection $(15.9 \%) .{ }^{8}$ Abuse and diversion of OxyContin decreased quarter-over-quarter for the first 5 years after the reformulation. ${ }^{9}$ One year after reformulation, the street price of OxyContin had dropped $36 \%$ versus the year before. ${ }^{9}$

Oxycodone was the subject of several reformulations in an effort to resist abuse (Table 2).

While the FDA has advocated for ADF opioid analgesics, these new ADF opioids have raised certain important concerns. First, will the wider availability of so-called ADF products cause prescribers to be less cautious about opioid prescribing, that is, will they engender a false sense of security that abuse is less likely? Another important question involves cost: will the use of ADFs result in greater costs to the already overtaxed health care system, since these products are generally more expensive than conventional, generic opioids? In a survey based on data from the IMS Health National Prescription Audit database, opioid prescriptions from 1992 to 2016 were analyzed. ${ }^{10}$ From 1992 to 2010, opioid analgesics were prescribed in steadily increasing numbers, but things changed in 2010 (the year reformulated OxyContin was introduced). From 2010 to 2015 , the number of dosing units per ER opioid prescription dropped 20\% (from 67 to 54) and the total weight of opioids prescribed in the USA decreased $16 \% .{ }^{10}$ The total number of dispensed opioid prescriptions decreased versus the previous year by $2.2 \%$ and $6.8 \%$ in 2014 and 2015, respectively. Thus, there are strong trends driving down opioid prescribing, among which the role of ADF products likely plays a part.

\section{ADF opioids are not perfect}

It is still possible to take ADF products intact orally and in some cases, the product can still be manipulated by skillful or dedicated abusers, many of whom publish their "hacks" online. Furthermore, it should be noted that the most commonly reported route of abuse for opioids is oral $(64.0 \%) .{ }^{11}$ However, death or major adverse effects are twice as likely to occur when prescription opioids are abused via non-oral routes of administration than when they are taken orally, such that ADF products have the potential to make a significant impact on public health. ${ }^{11}$

It is not realistic to consider that ADF opioids are abuseproof, but rather that they - like locks on cars - simply make certain forms of illegal acts more difficult, time consuming, cumbersome, and inconvenient. At best, ADF products help to deter abuse among those who are deliberately trying to tamper with the oral products in order to inhale, smoke, or inject the opioid. ADF products must be viewed with a balanced appraisal - they are at most one piece in the mosaic of things that can be done to minimize opioid misuse and abuse. $^{12}$

\section{Defining severe pain}

Opioids are frequently indicated in cases of severe pain of various etiologies including acute pain, traumatic pain, cancer pain, noncancer pain, and postsurgical pain. The World Health Organization in its seminal document on cancer pain treatment described pain in terms of intensity, identifying three levels (mild, moderate, severe). ${ }^{13}$ While pain is a multidimensional experience, ${ }^{14,15}$ pain intensity

Table 2 Oxycodone is available in several ADF products

\begin{tabular}{|c|c|c|}
\hline Brand name, manufacturer & Technology & Comment \\
\hline Oxytrex, Pain Therapeutics, Inc. & $\begin{array}{l}\text { Product uses an ultra-low dose of naltrexone }(0.000 \mathrm{I} \text { or } \\
0.00 \mathrm{l} \mathrm{mg}) \text { intended to enhance analgesia }\end{array}$ & $\begin{array}{l}\text { Not technically an ADF product; } \\
\text { investigational drug }\end{array}$ \\
\hline Roxybond ${ }^{\circledR}$, Inspirion Delivery Sciences & $\begin{array}{l}\text { SentryBond }{ }^{\circledR} \text { technology formulated with inactive ingredients } \\
\text { to make it difficult to crush or dissolve the pill }\end{array}$ & $\begin{array}{l}\text { Only immediate-release opioid in } \\
\text { ADF, approved in } 2017\end{array}$ \\
\hline Targiniq ${ }^{\circledR}$ ER, Purdue Pharma & Agonist/antagonist, crush-resistant technology & Approved in 2014 \\
\hline Troxyca ${ }^{\circledR}$ ER (ALO-02), Pfizer, Inc. & $\begin{array}{l}\text { Agonist/antagonist, ER oral capsules with film-coated beads. } \\
\text { Each bead has a core of sequestered naltrexone }\end{array}$ & Approved in 2016 \\
\hline Xtampza ${ }^{\circledR}$ ER, Collegium Pharmaceuticals & $\begin{array}{l}\text { Microspheres in the formulation make it difficult to extract } \\
\text { the opioids by crushing, grinding, or dissolving }\end{array}$ & Approved in 2016 \\
\hline
\end{tabular}

Abbreviations: ADF, abuse-deterrent formulation; ER, extended release. 
in and of itself remains a valuable and readily understood clinical metric. Pain is inherently subjective, but the tools to measure pain, such as the visual analog scale and variations or numeric rating scale, have been validated for use in clinical practice. ${ }^{16-19}$ Many tools generally consider pain $\geq 7$ on an 11-point scale to be "severe", ${ }^{20}$ but other studies suggest that the cutoff value between moderate and severe pain is 8 rather than $7 .^{21,22}$ Pain can also limit function, but pain severity is not linearly related to functional deficits. ${ }^{20}$ In fact, on an 11-point scale, the transitions from 4 to 5 and from 6 to 7 are the most influential differences in terms of functional limitations. ${ }^{20}$ Functional aspects of pain can be useful and relevant metrics, but do not necessarily correlate well with pain intensity. For example, a bedridden patient at the end of life may be in severe pain, but adequate analgesia may offer him/her no functional advantages. However, it can still be clinically relevant for many patients to discuss pain intensity in terms of function. In general, mild pain is such that many patients can go about their everyday activities with minimal disruption; mild pain may be troublesome, but is not necessarily a significant distraction to ordinary everyday life. Moderate pain, on the other hand, is more difficult to ignore. The patient may seek out medical care or pain treatment and it may limit the patient's activities to some degree. Moderate pain is much harder for the patient to ignore, although it may not yet reduce functionality in a substantial way. Finally, severe pain is impossible to ignore, likely decreases function, can disrupt sleep, and may adversely affect mood. ${ }^{20}$

While both cancer and noncancer pain rely on the designations mild, moderate, and severe to describe pain intensity, the experience of pain may be fundamentally different - and more severe - for cancer versus noncancer pain patients. For example, noncancer pain tends to be more stable than cancer pain, which may be associated with unpredictable episodes of breakthrough pain. Cancer pain can vary markedly from day to day or even hour to hour, and can worsen with disease progression and specific treatments. Since worsening cancer pain may be indicative of progressing disease, invading tumors, or a poor prognosis, exacerbated cancer pain carries with it emotional impact as well as physical pain. Certain forms of cancer pain, such as bone metastases, may interfere with function as well as cause pain, which may amplify the negative experience of pain. ${ }^{23}$ Thus, pain etiology may impact how patients perceive pain and how pain impacts them, although this has not been formally elucidated. ${ }^{23}$ For example, cancer patients report a significantly higher level of physical interference than noncancer pain patients even at the same level of pain intensity. ${ }^{24}$
It has been suggested that geriatric patients have lower pain thresholds than younger patients, ${ }^{25}$ but the physiologic reasons for these differences remain unclear. ${ }^{26}$ Intriguingly, recent studies have found obese individuals tend to have higher pain thresholds than nonobese individuals, ${ }^{27}$ although the reasons for this remain to be explored. Ethnic and culture differences may also impact how a patient perceives and responds to pain. ${ }^{28}$ Racial differentials in pain perception as well as pain experience have also been documented, ${ }^{29,30}$ but there is also evidence that there are racial disparities in terms of access to adequate analgesia. ${ }^{31}$ Thus, racial differences in pain perception may be caused by inadequate analgesia rather than truly different perceptions of pain. Gender may play a role as well; women tend to report more pain than men, ${ }^{32}$ but it has been suggested this has to do with gender roles rather than biology. ${ }^{33}$

Thus, clinicians treating patients in pain should be cognizant of the fact that the pain intensity is part of a much larger picture. Moreover, some patients may underreport their pain levels such that certain "moderate" pain syndromes may, in fact, reflect pain of severe intensity. There may be subtle gradations in the painful experiences of their patients based on the patient's pain etiology, diagnosis, prognosis, cultural background, and other factors. For these reasons, it is helpful to take a holistic approach to pain control and individualize analgesic regimens to meet the specific needs of the patient.

\section{Clinical studies}

ALO-02 has been evaluated in a variety of clinical studies for its abuse liability and its pain-relieving benefits in specific pain syndromes.

\section{Abuse potential}

In a double-blind, placebo- and active-controlled, six-way crossover study, 75 nondependent, recreational opioid users were randomized to take intact ALO-02 $40 \mathrm{mg}$, crushed ALO-02 40 and $60 \mathrm{mg}$, crushed IR oxycodone 40 and 60 mg (active control), or placebo. ${ }^{34}$ Compared to placebo, drug liking and reported time to maximum effect $\left(\mathrm{E}_{\max }\right)$ were significantly greater for oxycodone IR $(p<0.0001)$ than placebo; compared to oxycodone IR, both doses of crushed and intact ALO-02 were significantly lower in terms of likeability and $\mathrm{E}_{\max }(p<0.0001$ for both doses). Adverse events (AEs) were fewer in the ALO-02 groups compared to the oxycodone groups (from $71.1 \%$ to $91.9 \%$ versus $100 \%$, respectively). This study suggests that the oxycodone/naltrexone product has a lower abuse potential than oxycodone IR and is well tolerated. $^{34}$ 
A placebo- and active-controlled, double-blind, four-way, crossover study examined the abuse potential of crushed ALO02 inhaled nasally ("snorted") in healthy, nondependent, recreational opioid users. ${ }^{35} \mathrm{~A}$ total of 32 subjects were randomized to four groups: a crushed single dose of one of two placebos, a crushed dose of ALO-02 30/3.6 mg (oxycodone/naltrexone), or a crushed dose of oxycodone IR $30 \mathrm{mg}$. Crushed ALO-02 scored significantly lower than crushed oxycodone IR for drug liking and $\mathrm{E}_{\max }(60.5$ versus 92.8 , respectively, and 24.2 versus 86.9 , respectively; $p<0.0001)$. This suggests lower abuse potential for ALO-02 compared to oxycodone IR. ${ }^{35}$

A double-blind, placebo-controlled, three-way crossover study randomized 33 recreational nondependent opioid users to receive IV oxycodone $20 \mathrm{mg}$, IV crushed ALO-02 20/2.4 $\mathrm{mg}$ (oxycodone/naltrexone), or IV placebo. ${ }^{36}$ Drug liking was significantly greater for oxycodone than ALO-02 or placebo ( $p<0.0001$ for both); likewise, the quality of the psychoactive effect was significantly greater for oxycodone than placebo (but not significantly greater than ALO-02). ${ }^{36}$

"Dose dumping" occurs when a large amount of opioid is rapidly released from a controlled-release product, and it is one way that abusers seek to manipulate ER opioid products. Abusers may provoke dose dumping by taking the drug together with alcohol, in that some ER formulations are more soluble in alcohol than water. ${ }^{37,38}$ Furthermore, alcohol may also increase the permeability of drugs in the gastrointestinal tract. ${ }^{39}$ An open-label, single-dose, three-way crossover study randomized 18 healthy fasting subjects to be administered ALO-02 20/2.4 mg (oxycodone/naltrexone) under naltrexone block with one of three liquids: water, $20 \%$ ethanol, or $40 \%$ ethanol. ${ }^{40}$ Mean time to maximum concentration $\left(\mathrm{C}_{\max }\right)$ was 12 hours postdose for ALO-02 administered with water, but dropped to 8 hours when ALO- 02 was taken with $40 \%$ ethanol. The area under the plasma concentration time curve value from time zero extrapolated to infinity was similar for ALO-02 administered with water compared to $20 \%$ ethanol, but increased about $37 \%$ when ALO-02 was taken with $40 \%$ ethanol. The rate of AEs increased with ALO-02 plus ethanol versus ALO-02 with water. Thus, $\mathrm{C}_{\max }$ (which helps to define oxycodone exposure) increases with $40 \%$ ethanol but not with $20 \%$ ethanol, compared to ALO-02 taken with water. ${ }^{40}$

\section{Chronic low back pain and other chronic noncancer pain}

Chronic low back pain is a prevalent disorder and may be associated with severe pain. A double-blind, placebo-controlled study of patients with moderate to severe chronic low back pain was designed with an open-label phase of at least 4 weeks, during which all patients received ALO-02 at doses ranging from 20 to $160 \mathrm{mg} /$ day. ${ }^{41} \mathrm{In}$ the open-label phase of the study, the median daily dose of ALO- 02 was $20 \mathrm{mg}$ (mean $23.3 \mathrm{mg}$, range $10-160 \mathrm{mg}$ ), which increased to $60 \mathrm{mg}$ (mean $62.9 \mathrm{mg}$, range $10-160 \mathrm{mg}$ ) at the end of the open-label phase of about 4 weeks. The open-label phase was followed by a patient screening, and those who met the criteria (pain scores $\leq 4$, tolerated ALO-02, fixed dose established) could enter a double-blind study and were randomized to receive ALO-02 or placebo for 12 weeks with up to $3 \mathrm{~g}$ /day acetaminophen as rescue medication. A total of 663 patients were included in the study: 410 completed the open-label phase and 281 entered the double-blind phase. About a third of patients (31.5\%) discontinued participation in the study at the end of the open-label phase, most frequently because of AEs. Pain scores were significantly improved in ALO-02 patients from baseline to the 10th week of the study, with $44 \%$ of placebo and $57.5 \%$ of ALO- 02 patients reporting $\geq 30 \%$ improvement in pain scores. Upon entrance to the study, their overall pain scores were 7.0; the scores dropped to 3.1 at the conclusion of the open-label phase. In the open-label phase of the study, the median daily dose of ALO-02 was $20 \mathrm{mg}$ (mean 23.3 $\mathrm{mg}$, range $10-160 \mathrm{mg}$ ) and increased to $60 \mathrm{mg}$ (mean 62.9 $\mathrm{mg}$, range $10-160 \mathrm{mg}$ ) at the end of the open-label phase of about 4 weeks. During the double-blind phase, $43.3 \%$ of placebo and $34.9 \%$ of ALO-02 patients used rescue analgesia. Side effects were generally mild to moderate, with the most commonly reported AEs being nausea, constipation, and vomiting. ${ }^{41}$

Chronic noncancer pain describes a variety of painful conditions, including but not limited to musculoskeletal pain. In an open-label, year-long safety study, 395 patients with various types of moderate to severe chronic noncancer pain received ALO-02 at doses ranging from 20 to $160 \mathrm{mg}$ (oxycodone) per day ${ }^{42}$ Included in this study were both opioid-experienced and opioid-naïve patients. Pain severity scores on the Brief Pain Inventory Short Form decreased over time, and the most common treatment-emergent AEs were nausea (25.3\%), constipation $(21.3 \%)$, vomiting $(13.9 \%)$, and headache $(11.6 \%)$. The most frequently reported drug-related AEs were constipation (18.0\%), nausea (14.9\%), somnolence (8.4\%), fatigue (6.8\%), dizziness $(5.6 \%)$, and vomiting $(5.1 \%) .^{42}$

\section{Clinical issues}

When arriving at a prescribing choice for the control of pain severe enough to require daily, around-the-clock, long-term opioid treatment and for which alternative treatment options are inadequate, a series of important clinical decisions are 
required. These questions are evaluated in the following section with the focus on ADF oxycodone/naltrexone as an option.

\section{When to consider opioid analgesia}

As a general rule, opioids are not usually the first-line agents to manage pain unless the pain is acute (e.g., traumatic pain or postsurgical pain) or overwhelmingly severe. Guidelines for various pain syndromes usually specify that nonopioid analgesics, such as acetaminophen, and nonsteroidal antiinflammatory drugs be utilized first and opioids trialed only if nonopioid therapy does not offer adequate analgesia. ${ }^{43-50}$ Thus, patients with pain associated with osteoarthritis may first be administered acetaminophen or nonsteroidal antiinflammatory drugs and progress to opioids only if these agents do not provide adequate pain control.

Opioid therapy in an opioid-naïve patient should commence as a trial rather than the initiation of long-term therapy. The patient and caregivers should be informed about the potential risks as well as benefits of opioid therapy. In some cases, informed consent or another type of agreement should be signed to assure that the patient understands not just the risks of opioid therapy but the clinician's expectation for patient compliance as well. Patients should be educated about possible side effects, so that they are reported promptly. Clinicians should consider opioid therapy only if the expected benefits for both pain and function are anticipated to outweigh the risks to the patient. ${ }^{51}$ Before starting opioid therapy for chronic pain, clinicians should establish treatment goals with all patients, including realistic goals for pain and function, and should consider how therapy will be discontinued if the benefits do not outweigh the risks. ${ }^{51}$ Clinicians should review the patient's history of controlled substance prescriptions using state prescription drug monitoring program data to determine whether the patient is receiving opioid dosages or dangerous combinations that put him or her at high risk for overdose. ${ }^{51}$ Clinicians should review prescription drug monitoring program data when starting opioid therapy for chronic pain. ${ }^{51}$

Opioids should be started at a low dose under close supervision; not all patients tolerate them well. Pain should be evaluated and discussed frequently, as not all patients find effective pain control with opioids. In some cases, pain control may improve with changes in dose or opioid rotation, but in other cases, patients may decide that opioids are not effective. It should be noted that opioids are not necessarily appropriate for all pain syndromes, including the severe pain associated with migraine and fibromyalgia. ${ }^{52}$

Before starting opioid therapy, universal precautions should be exercised, ${ }^{53}$ so that the patients at risk for poten- tial opioid misuse and abuse can be identified. Clinicians should talk frankly with their patients about the nature of opioid therapy. A variety of validated screening tools exist to assess opioid abuse risk in individual patients. ${ }^{54-56}$ The most prominent risk factor for opioid abuse is a history of active substance abuse, but there are multiple risk factors. In fact, long-term opioid therapy itself may be a risk for abuse. ${ }^{57}$ For patients at risk of opioid abuse, ADF formulations can be an important option.

Opioids should be considered only when their potential analgesic benefits outweigh their associate side effects. ${ }^{58}$ Opioid-associated side effects are well documented in the literature and can be treatment limiting. ${ }^{59}$ Many AEs can be managed, which is important because side effects can increase discomfort in patients already at great distress due to pain.

\section{When to consider ADFs of opioids}

ADF products may be appropriate for patients in severe pain even if these patients themselves are not at elevated risk for opioid abuse. Long-term opioids are typically dispensed as a 30-day supply, or even more, meaning that a number of pills will be stored in the household and could be purloined by other household members or guests. Recreational opioid users report that they can often get drugs by stealing them from friends and family members. ${ }^{60}$ Thus, ADF oxycodone may be an important product for outpatient use in busy or multi-person households where drugs may not be carefully secured between doses.

Only a subset of opioid analgesics is available in ADF formulations and none are generic. ADF products cost more than their generic counterparts, a factor that can play a major role in product selection. Indeed, many payers may not reimburse for ADF opioids. An argument may be made that since most patients prescribed opioids will not abuse them, they derive no benefit from ADF products and should therefore not have to pay the incremental costs for ADF technology. ADF products are still important in that they are designed to resist or deter abuse, whether it is carried out by the patient or a person who has access to that patient's drugs. Furthermore, as ADF products increasingly crowd out conventional, non-ADF opioids in the marketplace, prescription opioids become more difficult to abuse overall.

\section{Opioid rotation}

Opioid rotation - switching from one opioid type and formulation to another - is a recognized analgesic strategy and can be used before abandoning opioid therapy when the patient has inadequate analgesia or intolerable side effects 
on the current regimen. ${ }^{61}$ Strategies to convert the doses of the opioids have been published, ${ }^{62,63}$ but generally involve establishing an equianalgesic dose and then starting the patient on a somewhat lower than equianalgesic dose of the new opioid and titrating slowly and carefully to achieve pain relief with tolerable side effects.

In some cases, it may be helpful to rotate a patient from a conventional product to an ADF formulation. It should be noted that not all opioid products are available in an ADF formulation. There may be occasions when the patient must discontinue an ADF product and move to another opioid which is not available in ADF version. In this case, clinicians must consider whether the patient is genuinely experiencing a lack of efficacy and/or treatment-limiting side effects or the patient may simply want to manipulate the clinician into prescribing a different opioid that may be more vulnerable to tampering. ${ }^{64}$

Of course, rotating a conventional non-ADF opioid product to an $\mathrm{ADF}$ formulation does not necessarily mean no abuse will occur. ${ }^{64} \mathrm{ADF}$ products are still vulnerable to abuse by those who wish to ingest them intact orally, and, in some cases, ADF products can be "hacked" by those resourceful enough to figure out strategies to defeat the ADF mechanisms.

\section{Treating severe pain in opioid- experienced patients}

If patients with severe pain are opioid experienced, tolerance has likely developed with prolonged opioid exposure. Opioids should be titrated to the effective dosage, which may be high in opioid-experienced patients with severe pain. It is important to consider carefully complaints raised by patients about inadequate analgesia. In some cases, the patients may be experiencing tolerance, in which cases, judicious titration to a higher dose of opioids is appropriate. Tolerance to one opioid may also be addressed by rotating to a different opioid which may be effective at lower doses. In other cases, the patient may ask for higher doses because he or she is seeking to obtain more drugs. It is also important to consider the seemingly paradoxical condition of opioid-induced hyperalgesia in which prolonged exposure to opioids lowers the pain threshold. In the latter case, opioids should be tapered and discontinued in favor of a different analgesic regimen. ${ }^{65}$

The Centers for Disease Control and Prevention have advocated against high doses of opioids. ${ }^{51}$ However, high doses of opioids for individual patients might be justified, particularly for palliative care cancer patients at the end of life or patients in severe or very severe pain of likely limited duration (e.g., traumatic injury, burn patients, severe postsurgical pain). The use of high-dose opioid therapy may increase the risk of opioid abuse. ${ }^{66}$ In addition, high-dose opioid therapy has been associated with other health-related concerns, more severe pain intensities, and greater utilization of health care resources. ${ }^{67-69}$

\section{Treating pain in active substance abusers}

Prescribers increasingly face the conundrum of having to manage pain in past or even active substance abusers. For example, heroin addicts are not rare and their propensity to suffer from painful infections and osteomyelitis along with overdose and other conditions means that they frequently are managed by the health care system. Yet, the literature contains very little with respect to how to manage pain in heroin addicts. There are several key considerations for this population. First, heroin abusers may not be forthcoming about their addiction, particularly if they fear that honesty might result in legal repercussions or that they might be denied medical care and/or pain control. Second, even if heroin abusers are transparent about their drug use, street heroin is frequently cut with fentanyl or other adulterants and purity varies widely - it is practically impossible for heroin addicts to accurately report what drug(s) and how much they are taking. Third, few clinicians feel confident in treating them. ${ }^{70}$ Finally, heroin addicts (like opioid-experienced patients) typically have developed tolerance, such that relatively high and/or frequent doses of opioids are needed to control their acute pain.

The notion that opioid addicts do not feel pain is a myth. Opioid addicts in acute pain may be administered opioid analgesics at a dose needed to manage both pain and withdrawal symptoms, but it is important to discuss the pain management plan in advance to manage patient and provider expectations.

Also encountered in clinical practice are patients on medication-assisted therapies to treat opioid abuse, such as methadone maintenance programs or buprenorphine maintenance. They also pose a challenge for clinical pain management. Such patients often have high tolerance to opioids, but their opioids - which may be dosed only every 24 or 48 hours - likely provide little analgesic benefit. In such cases, the medication-assisted therapy should be continued with short-acting opioids prescribed to provide acute pain control. ${ }^{71}$

The idea that a substance abuser with a legitimate pain syndrome should be denied pain control cannot be supported. However, long-term pain control in substance abusers becomes problematic.

Many opioid addicts have or have had legitimate painful conditions. In a survey of 199 young subjects (mean age 24.6 years) in which $59.8 \%$ of participants reported nonmedical use of a prescription opioid at least once a week, 
the majority of subjects said that at one time or another, they had severe pain $(86.2 \%$ of men and $84.1 \%$ of women $) .{ }^{72}$ Of these patients, most said that they used prescription opioids nonmedically to treat their pain $(72.3 \%$ of men and $81.2 \%$ of women) and that their physician(s) had refused to prescribe opioids to them to treat their severe pain $(26.9 \%$ of men and $36.2 \%$ of women). In this survey, reporting higher intensities of physical pain could be statistically correlated to nonmedical use of opioids ( $p=0.002) .{ }^{72}$ This suggests that denying pain therapy to opioid abusers simply drives them to find illicit substances. In a retrospective database study (2006-2015) evaluating 5,307 adult patients diagnosed with an opioid use disorder, $61.8 \%$ had some sort of chronic painful condition prior to being diagnosed with an opioid use disorder. ${ }^{73}$

Long-term pain therapy for those with a history of substance abuse or with active substance use disorder can be highly problematic. It must begin with a frank discussion between doctor and patient about the nature of the painful condition as well as the patient's opioid abuse. A patient-provider agreement should be worked out and put into writing describing the expectations of therapy. ADF products are appropriate for such patients, even if they claim that they would not inhale or inject an opioid. The exact strategies for managing pain in patients with substance abuse disorders goes beyond the scope of this article, but is an important and extremely timely clinical topic.

\section{Conclusion}

Oxycodone ER is an effective pain reliever for severe pain, and its incorporation into an ADF product with sequestered naltrexone is designed to resist abuse by those who want to smoke, inhale, or inject the active agent. ALO-02 is a novel product that may be a versatile and useful addition to the armamentarium of pain relievers.

\section{Acknowledgment}

The authors wish to acknowledge and thank John Bisney for his expert editorial assistance and discussions.

\section{Disclosure}

JVP consults for multiple pharmaceutical companies involved in the discovery/development of analgesics, and is the cofounder of NEMA Research and Neumentum, a non-opioid analgesics company. RBR consults for several pharmaceutical companies involved in analgesics drug discovery/development, but receives no royalties for sales of any product, and is investor in Neumentum and co-founder of CaRafe, both non-opioid analgesics discovery/development companies. The authors report no other conflicts of interest in this work.

\section{References}

1. Food and Drug Administration. Abuse-deterrent opioid medications. FDA Facts 2017. Available from: https://www.fda.gov/newsevents/ newsroom/factsheets/ucm514939.htm. Accessed March 31, 2017.

2. Maincent J, Zhang F. Recent advances in abuse-deterrent technologies for the delivery of opioids. Int J Pharm. 2016;510(1):57-72.

3. Senay EC. Clinical experience with T's and B's. Drug Alcohol Depend. 1985;14(3-4):305-312.

4. Reed DA, Schnoll SH. Abuse of pentazocine-naloxone combination. JAMA. 1986;256(18):2562-2564.

5. Baum C, Hsu JP, Nelson RC. The impact of the addition of naloxone on the use and abuse of pentazocine. Public Health Rep. 1987;102(4):426-429.

6. Lahmeyer HW, Craig RJ. Pentazocine naloxone: another "addictionproof" drug of abuse. Int J Addict. 1987;22(11):1163-1166.

7. Hays LR. A profile of OxyContin addiction. JAddict Dis. 2004;23(4):1-9.

8. Butler SF, Black RA, Cassidy TA, Dailey TM, Budman SH. Abuse risks and routes of administration of different prescription opioid compounds and formulations. Harm Reduct J. 2011;8:29.

9. Severtson SG, Ellis MS, Kurtz SP, et al. Sustained reduction of diversion and abuse after introduction of an abuse deterrent formulation of extended release oxycodone. Drug Alcohol Depend. 2016;168:219-229.

10. Pezalla EJ, Rosen D, Erensen JG, Haddox JD, Mayne TJ. Secular trends in opioid prescribing in the USA. J Pain Res. 2017;10:383-387.

11. Green JL, Bucher Bartelson B, Le Lait MC, et al. Medical outcomes associated with prescription opioid abuse via oral and non-oral routes of administration. Drug Alcohol Depend. 2017;175:140-145.

12. Becker WC, Fiellin DA. Abuse-deterrent opioid formulations - putting the potential benefits into perspective. $N$ Engl J Med. 2017; 376(22):2103-2105.

13. World Health Organization. WHO's pain ladder for adults; 1988. Available from: http://www.who.int/cancer/palliative/painladder/en/. Accessed May 7, 2013.

14. Snelgrove S, Liossi C. Living with chronic low back pain: a metasynthesis of qualitative research. Chronic Illn. 2013;9(4):283-301.

15. Doleys DM, Brown JL, Ness T. Multidimensional outcomes analysis of intrathecal, oral opioid, and behavioral-functional restoration therapy for failed back surgery syndrome: a retrospective study with 4 years' follow-up. Neuromodulation. 2006;9(4):270-283.

16. Tan G, Jensen MP, Thornby JI, Shanti BF. Validation of the brief pain inventory for chronic nonmalignant pain. J Pain. 2004;5(2):133-137.

17. Garra G, Singer AJ, Taira BR, et al. Validation of the Wong-Baker FACES Pain Rating Scale in pediatric emergency department patients. Acad Emerg Med. 2010;17(1):50-54.

18. Caraceni A. Evaluation and assessment of cancer pain and cancer pain treatment. Acta Anaesthesiol cand. 2001;45(9):1067-1075.

19. Dijkers M. Comparing quantification of pain severity by verbal rating and numerical rating scales. J Spinal Cord med. 2010;33(3):232-242.

20. Serlin RC, Mendoza TR, Nakamura Y, Edwards KR, Cleeland CS. When is cancer pain mild, moderate or severe? Grading pain severity by its interference with function. Pain. 1995;61(2):277-284.

21. Hirschfeld G, Zernikow B. Cut points for mild, moderate, and severe pain on the VAS for children and adolescents: what can be learned from 10 million ANOVAs? Pain. 2013;154(12):2626-2632.

22. Hirschfeld G, Zernikow B. Variability of "optimal" cut points for mild, moderate, and severe pain: neglected problems when comparing groups. Pain. 2013;154(1):154-159.

23. Paul SM, Zelman DC, Smith M, Miaskowski C. Categorizing the severity of cancer pain: further exploration of the establishment of cutpoints. Pain. 2005;113(1-2):37-44.

24. Holen JC, Lydersen S, Klepstad P, Loge JH, Kaasa S. The brief pain inventory: pain's interference with functions is different in cancer pain compared with noncancer chronic pain. Clin J Pain. 2008;24(3):219-225.

25. Gibson SJ, Helme RD. Age-related differences in pain perception and report. Clin Geriatr Med. 2001;17(3):433-456, v-vi.

26. Gibson SJ, Farrell M. A review of age differences in the neurophysiology of nociception and the perceptual experience of pain. Clin J Pain. 2004;20(4):227-239. 
27. Torensma B, Thomassen I, van Velzen M, In 't Veld BA. Pain experience and perception in the obese subject systematic review (revised version). Obesity Surg. 2016;26(3):631-639.

28. Kwok W, Bhuvanakrishna T. The relationship between ethnicity and the pain experience of cancer patients: a systematic review. Indian J Palliat Care. 2014;20(3):194-200.

29. Lavernia CJ, Alcerro JC, Rossi MD. Fear in arthroplasty surgery: the role of race. Clin Orthop Relat Res. 2010;468(2):547-554.

30. Lavernia CJ, Alcerro JC, Contreras JS, Rossi MD. Ethnic and racial factors influencing well-being, perceived pain, and physical function after primary total joint arthroplasty. Clin Orthop Relat Res. 2011;469(7):1838-1845.

31. Shah AA, Zogg CK, Zafar SN, et al. Analgesic access for acute abdominal pain in the emergency department among racial/ethnic minority patients: a nationwide examination. Med Care. 2015;53(12):1000-1009.

32. Soetanto AL, Chung JW, Wong TK. Are there gender differences in pain perception? J Neurosci Nurs. 2006;38(3):172-176.

33. Alabas OA, Tashani OA, Tabasam G, Johnson MI. Gender role affects experimental pain responses: a systematic review with meta-analysis. Eur J Pain. 2012;16(9):1211-1223.

34. Setnik B, Bass A, Bramson C, et al. Abuse Potential Study of ALO-02 (Extended-Release Oxycodone Surrounding Sequestered Naltrexone) compared with immediate-release oxycodone administered orally to nondependent recreational opioid users. Pain Med. 2017;18(6):1077-1088.

35. Setnik B, Bramson C, Bass A, et al. Intranasal administration of crushed ALO-02 (extended-release oxycodone with sequestered naltrexone): a randomized, controlled, abuse potential study in nondependent recreational opioid users. J Clin Pharmacol. 2015;55(12):1351-1361.

36. Backonja M, Webster LR, Setnik B, et al. Intravenous abuse potential study of oxycodone alone or in combination with naltrexone in nondependent recreational opioid users. Am J Drug Alcohol Abuse. 2016;42(5):539-549.

37. Jedinger N, Khinast J, Roblegg E. The design of controlled-release formulations resistant to alcohol-induced dose dumping a review. Eur J Pharm Biopharm. 2014;87(2):217-226.

38. Jedinger N, Schrank S, Mohr S, Feichtinger A, Khinast J, Roblegg E. Alcohol dose dumping: the influence of ethanol on hot-melt extruded pellets comprising solid lipids. Eur J Pharm Biopharm. 2015;92:83-95.

39. Volpe DA, Asafu-Adjaye EB, Ellison CD, Doddapaneni S, Uppoor RS, Khan MA. Effect of ethanol on opioid drug permeability through caco-2 cell monolayers. AAPS J. 2008;10(2):360-362.

40. Malhotra BK, Matschke K, Wang Q, Bramson C, Salageanu J. Effects of ethanol on the pharmacokinetics of extended-release oxycodone with sequestered naltrexone (ALO-02). Clin Drug Investig. 2015;35(4):267-274.

41. Rauck RL, Hale ME, Bass A, et al. A randomized double-blind, placebocontrolled efficacy and safety study of ALO-02 (extended-release oxycodone surrounding sequestered naltrexone) for moderate-to-severe chronic low back pain treatment. Pain. 2015;156(9):1660-1669.

42. Arora S, Setnik B, Michael D, et al. A multicenter, 12-month, open-label, single-arm safety study of oxycodone-hydrochloride/naltrexone-hydrochloride extended-release capsules (ALO-02) in patients with moderateto-severe chronic noncancer pain. J Opioid Manag. 2014;10(6):423-436.

43. Alford DP. Chronic back pain with possible prescription opioid misuse. JAMA. 2013;309(9):919-925.

44. American Geriatrics Society. AGS Clinical Practice Guideline: Pharmacological management of persistent pain in older persons; 2013. Available from: http://www.americangeriatrics.org/health_care_professionals/clinical_practice/clinical_guidelines_recommendations/ persistent_pain_executive_summary. Accessed December 14, 2013.

45. American Pain Society. Guideline for the management of cancer pain in adults and children; 2004. Available from: http://apps.americanpainsociety.org/Default.aspx?TabID=251\&ProductId=472. Accessed August 10, 2013.

46. Ho KY, Chua NH, George JM, et al; Pain Association of Singapore Task Force. Evidence-based guidelines on the use of opioids in chronic non-cancer pain - a consensus statement by the Pain Association of Singapore Task Force. AnnAcad Med Singapore. 2013;42(3):138-152.
47. Zhang W, Moskowitz RW, Nuki G, et al. OARSI recommendations for the management of hip and knee osteoarthritis, Part II: OARSI evidence-based, expert consensus guidelines. Osteoarthritis Cartilage. 2008;16(2):137-162.

48. Zhang W, Doherty M, Arden N, et al; EULAR Standing Committee for International Clinical Studies Including Therapeutics (ESCISIT). EULAR evidence based recommendations for the management of hip osteoarthritis: report of a task force of the EULAR Standing Committee for International Clinical Studies Including Therapeutics (ESCISIT). Ann Rheum Dis. 2005;64(5):669-681.

49. Zhang W, Doherty M, Bardin T, et al; EULAR Standing Committee for International Clinical Studies Including Therapeutics. EULAR evidence based recommendations for gout. Part II: Management. Report of a task force of the EULAR Standing Committee for International Clinical Studies Including Therapeutics (ESCISIT). Ann Rheum Dis. 2006;65(10):1312-1324.

50. Zhang W, Doherty M, Leeb BF, et al. EULAR evidence based recommendations for the management of hand osteoarthritis: report of a Task Force of the EULAR Standing Committee for International Clinical Studies Including Therapeutics (ESCISIT). Ann Rheum Dis. 2007;66(3):377-388.

51. Dowell D, Haegerich TM, Chou RC. CDC Guideline for prescribing opioids for chronic pain - United States, 2016. MMWR Recomm Rep. 2016;65(1):1-49.

52. Littlejohn GO, Guymer EK, Ngian GS. Is there a role for opioids in the treatment of fibromyalgia? Pain Manag. 2016;6(4):347-355.

53. Gourlay DL, Heit HA. Universal precautions revisited: managing the inherited pain patient. Pain Med. 2009;10(Suppl 2):S115-S123.

54. Butler SF, Budman SH, Fernandez KC, Fanciullo GJ, Jamison RN. Cross-validation of a screener to predict opioid misuse in chronic pain patients (SOAPP-R). J Addict Med. 2009;3(2):66-73.

55. Chou R, Fanciullo GJ, Fine PG, Miaskowski C, Passik SD, Portenoy RK. Opioids for chronic noncancer pain: prediction and identification of aberrant drug-related behaviors: a review of the evidence for an American Pain Society and American Academy of Pain Medicine clinical practice guideline. J Pain. 2009;10(2):131-146.

56. Moore TM, Jones T, Browder JH, Daffron S, Passik SD. A comparison of common screening methods for predicting aberrant drug-related behavior among patients receiving opioids for chronic pain management. Pain Med. 2009;10(8):1426-1433.

57. Smith HS, Kirsh KL, Passik SD. Chronic opioid therapy issues associated with opioid abuse potential. J Opioid Manag. 2009;5(5): 287-300.

58. Manchikanti L, Kaye AM, Knezevic NN, et al. Responsible, safe, and effective prescription of opioids for chronic non-cancer pain: American Society of Interventional Pain Physicians (ASIPP) Guidelines. Pain Physician. 2017;20(2S):S3-S92.

59. Camilleri M. Opioid-induced constipation: challenges and therapeutic opportunities. Am J Gastroenterol. 2011;106(5):835-842; quiz 843.

60. Wawrzyniak KM, Sabo A, McDonald A, et al. Root cause analysis of prescription opioid overdoses. J Opioid Manag. 2015;11(2): 127-137.

61. Nalamachu SR. Opioid rotation in clinical practice. Adv Ther. 2012;29(10):849-863.

62. Mercadante S, Bruera E. Opioid switching: a systematic and critical review. Cancer Treat Rev. 2006;32(4):304-315.

63. Mercadante S, Caraceni A. Conversion ratios for opioid switching in the treatment of cancer pain: a systematic review. Palliat Med. 2011;25(5):504-515.

64. Pappagallo M, Sokolowska M. The implications of tamper-resistant formulations for opioid rotation. Postgrad Med. 2012;124(5):101-109.

65. Carullo V, Fitz-James I, Delphin E. Opioid-induced hyperalgesia: a diagnostic dilemma. J Pain Palliat Care Pharmacother. 2015; 29(4):378-384.

66. Cheatle MD. Prescription opioid misuse, abuse, morbidity, and mortality: balancing effective pain management and safety. Pain Med. 2015;16(Suppl 1):S3-S8. 
67. Sullivan MD, Howe CQ. Opioid therapy for chronic pain in the United States: promises and perils. Pain. 2013;154(Suppl 1):S94-S100.

68. Kobus AM, Smith DH, Morasco BJ, et al. Correlates of higher-dose opioid medication use for low back pain in primary care. J Pain. 2012; 13(11):1131-1138.

69. Merrill JO, Von Korff M, Banta-Green CJ, et al. Prescribed opioid difficulties, depression and opioid dose among chronic opioid therapy patients. Gen Hosp Psychiatry. 2012;34(6):581-587.

70. Hagemeier NE, Gray JA, Pack RP. Prescription drug abuse: a comparison of prescriber and pharmacist perspectives. Subst Use Misuse. 2013;48(9):761-768.
71. Raub JN, Vettese TE. Acute pain management in hospitalized adult patients with opioid dependence: a narrative review and guide for clinicians. J Hosp Med. 2017;12(5):375-379.

72. Evans TI, Liebling EJ, Green TC, Hadland SE, Clark MA, Marshall BDL. Associations between physical pain, pain management, and frequency of nonmedical prescription opioid use among young adults: a sex-specific analysis. J Addic Med. 2017;11(4): 266-272.

73. Hser YI, Mooney LJ, Saxon AJ, Miotto K, Bell DS, Huang D. Chronic pain among patients with opioid use disorder: results from electronic health records data. J Subst Abuse Treat. 2017;77:26-30.
Journal of Pain Research

\section{Publish your work in this journal}

The Journal of Pain Research is an international, peer reviewed, open access, online journal that welcomes laboratory and clinical findings in the fields of pain research and the prevention and management of pain. Original research, reviews, symposium reports, hypothesis formation and commentaries are all considered for publication.

\section{Dovepress}

The manuscript management system is completely online and includes a very quick and fair peer-review system, which is all easy to use. Visit http://www.dovepress.com/testimonials.php to read real quotes from published authors. 